\section{Case Reports in Ophthalmology}

Case Rep Ophthalmol 2020;11:534-539

DOI: 10.1159/000509527

Published online: October 14, 2020
(C) 2020 The Author(s)

Published by S. Karger AG, Basel www.karger.com/cop

This article is licensed under the Creative Commons Attribution-NonCommercial 4.0 International License (CC BY-NC) (http://www.karger.com/Services/OpenAccessLicense). Usage and distribution for commercial purposes requires written permission.

\title{
Globe Subluxation following Long-Term High-Dose Steroid Treatment for Myasthenia Gravis
}

\author{
Jasmien Dam ${ }^{a}$ Florit Marcuse $^{b} \quad$ Marc De Baets $^{b} \quad$ Catherine Cassiman $^{a}$ \\ ${ }^{\mathrm{a} O p h t h a l m o l o g y, ~ U Z ~ L e u v e n, ~ L e u v e n, ~ B e l g i u m ; ~}{ }^{\mathrm{b}} \mathrm{MHeNS}$ School for Mental Health and \\ Neuroscience, Maastricht University, Maastricht, The Netherlands
}

\section{Keywords}

Myasthenia gravis $\cdot$ Globe subluxation $\cdot$ Steroids

\begin{abstract}
This case report describes the unusual presentation of a globe subluxation following longterm high-dose oral steroid treatment for myasthenia gravis (MG). The patient presented initially with fluctuating vertical diplopia. Auto-antibodies against the acetylcholine receptor were weakly positive, confirming the diagnosis of MG. After initial treatment with pyridostigmine, the disease evolved to generalized MG. Plasmapheresis and high-dose steroids were started subsequently. As a side effect of this treatment the patient gained about $30 \mathrm{~kg}$ in weight and developed steroid myopathy and a prominent cushingoid facies with bilateral exophthalmos. A year after his initial diagnosis he experienced a spontaneous globe subluxation on the left eye. He was able to immediately reposition the globe manually himself. Four months later a new subluxation occurred. Because of these aforementioned severe side effects of the steroid treatment, the methylprednisolone was tapered and replaced by tacrolimus. After about 6 weeks the patient went into remission. We believe, that the spontaneous globe subluxations were caused by a weakness of the extraocular muscles in combination with a significant gain of intraorbital fat tissue, both induced by cumulative, excessive steroids. Steroids are often necessary in the treatment of MG; however, most of the time a high dose of $64 \mathrm{mg}$ is not needed for ocular MG and especially the continuation of a dose of $58 \mathrm{mg}$ or more for a long period is not recommended. Careful follow-up is obligatory to timely recognize side effects. In case of severe side effects or the need for long-term treatment, the use of other immunosuppressive therapies should be considered. Extra care and caution is recommended in patients who are anatomically predisposed with proptosis.




\section{Case Reports in Ophthalmology}

\begin{tabular}{l|l}
\hline DOI: $10.1159 / 000509527$ & ๑ 2020 The Author(s). Published by S. Karger AG, Basel \\
\hline
\end{tabular} www.karger.com/cop

Dam et al.: Globe Subluxation following Long-Term High-Dose Steroid Treatment for Myasthenia Gravis

\section{Introduction}

Myasthenia gravis (MG) is an autoimmune disorder of the postsynaptic neuromuscular junction resulting in muscle weakness and fatigability. Of all MG patients, $85 \%$ present with ocular signs and symptoms, the most common being fluctuating ptosis [1,2]. Other symptoms include strabismus, which can clinically mimic an external ophthalmoplegia or a single or multiple motor cranial nerve palsy. About $17 \%$ of all MG patients only have ocular symptoms. The majority of MG patients however develop generalized muscle weakness, mostly within 2 years after start of the first symptoms of MG. Treatment options for MG consist of acetylcholinesterase inhibitors and in more severe cases immunosuppressive drugs and biologicals (rituximab). Surgical treatment (thymectomy) has a beneficial effect in reducing symptoms and using less steroids [3].

\section{Case Presentation}

A 57-year-old healthy male presented at the Department of Ophthalmology with fluctuating vertical diplopia. Orthoptic examination demonstrated weakness of the inferior rectus muscle. Ocular examination showed an inborn tendency towards proptosis. There were no signs of ptosis. The diagnosis of MG was established by the presence of acetylcholine receptor auto-antibodies. Single-fiber electromyography of the frontal muscle and computed tomography of the brain were normal. Thyroid-stimulating hormone (TSH), Thyroid stimulating immunoglobulin (TSI), anti-thyroglobulin (anti-Tg), and anti-thyroid peroxidase (anti-TPO) were absent. Initially, he showed a good clinical response to pyridostigmine in increasing dose up to $720 \mathrm{mg}$. But after 2 months, his ocular symptoms worsened and he started to experience abdominal cramps secondary to the high doses of pyridostigmine. Plasmapheresis was started and pyridostigmine was tapered to $600 \mathrm{mg}$. The patient reported initially an improvement of his symptoms after plasmapheresis, but 3 months later, he developed a full ptosis of his left eye. His neurologist then started oral steroid treatment (64 mg methylprednisolone) and increased the dose of pyridostigmine to $720 \mathrm{mg}$. This resulted in a rapid clinical improvement. One year after his diagnosis of MG he presented again at the emergency Department of Ophthalmology. The patient described he had experienced a sudden protrusion of the left eye with inability to close the eyelids upon awakening. This description fits with a globe subluxation. Fortunately, he had been able to push the globe back himself, causing a big corneal abrasion. By this time, he had already been on $58 \mathrm{mg}$ of methylprednisolone for 6 months. Pyridostigmine had been tapered to $360 \mathrm{mg}$ because of the gastrointestinal side effects. Ocular motility examination showed improvement of the ductions. His intraocular pressure was elevated, 22 $\mathrm{mm} \mathrm{Hg}$ in the right and $26 \mathrm{~mm} \mathrm{Hg}$ in the left eye (ATO). Therefore, topical prostaglandin treatment was initiated to control the intraocular pressure. The patient had gained about $30 \mathrm{~kg}$ and had developed a significant cushingoid facies over the past 6 months (Fig. 1). He was unable to climb stairs or carry a bucket of water due to steroid myopathy in conjunction with generalized MG. As the treatment of his disease was not according to international recommendations, he was referred to a different neurologist (M.D.B.), who tapered methylprednisolone and pyridostigmine and added $3 \mathrm{mg}$ of tacrolimus. This resulted in a quick remission. Just 10 weeks after the introduction of tacrolimus to the treatment, the methylprednisolone could already be tapered to $4 \mathrm{mg}$. Two months later however, a new subluxation occurred, despite optimal medical treatment. To avoid new subluxations lateral tarsorrhaphy was performed. 


\section{Case Reports in Ophthalmology}

\begin{tabular}{l|l}
\hline DOI: 10.1159/000509527 & @ 2020 The Author(s). Published by S. Karger AG, Basel \\
\hline
\end{tabular} www.karger.com/cop

Dam et al.: Globe Subluxation following Long-Term High-Dose Steroid Treatment for Myasthenia Gravis

\section{Discussion}

Spontaneous globe luxation is a rare condition which occurs when the equator of the globe protrudes anterior to the orbital rim. It can result in keratopathy or corneal abrasion or even optic neuropathy secondary to stretching of the optic nerve. Globe subluxation is most commonly associated with thyroid eye disease (Graves' eye disease), shallow orbit, and floppy eye syndrome. Globe subluxations caused by general anesthesia [4] or retrobulbar space-occupying lesions have been reported as well. In anatomically predisposed patients this distressful event can occur after Valsalva maneuver and eye or lid manipulation [5]. In MG patients, a second auto-immune disorder, especially thyroid diseases, frequently occurs. In Graves' eye disease, an increase in retro-orbital fat and myositis occurs. Therefore, it should be considered in the differential diagnosis of MG patients with proptosis and TSH, TSI, anti$\mathrm{Tg}$, and anti-TPO should be analyzed. This patient showed no signs of floppy eyelid syndrome. His TSH level was normal and TSI, anti-Tg, and anti-TPO were negative. As he showed no other signs of thyroid eye disease apart from the proptosis and the MRI showed only increased orbital fat and atrophic muscles rather than hypertrophy (Fig. 2), we do not believe he had thyroid eye disease. Therefore, this is the first case of spontaneous globe subluxation associated with MG threated with long-term high-dose steroids. This patient was predisposed because of his natural physiognomy with slight proptosis. We believe that the globe subluxation in this case was caused by a combination of increased retro-orbital fat tissue and myopathy of the extraocular muscles (Fig. 2), both induced by long-term high-dose steroid therapy in an anatomically predisposed orbit.

Steroids are part of the first-line treatment for MG; however, a high dose of $64 \mathrm{mg}$ is often not necessary for ocular MG. Moreover, the continuation of a dose of $58 \mathrm{mg}$ or more for more than 6 months is not recommended.

Side effects, like myopathy, are commonly seen with steroid treatment. Careful follow-up is necessary to adjust treatment in case of serious side effect. Extra care and caution must be taken in anatomically predisposed patients with proptosis. In case of prolonged need for treatment, other forms of immunosuppressive therapy, e.g., azathioprine, tacrolimus, should be considered.

\section{Statement of Ethics}

Written informed consent was obtained from the patient for publication of this report and any presented images.

\section{Conflict of Interest Statement}

The authors have no conflict of interest to declare.

\section{Funding Sources}

None. 


\section{Author Contributions}

J.D.: first draft of paper and final revision. J.D. and F.M.: co-writing of manuscript, literature search, reviewing and editing. C.C. and M.D.B.: patient management, manuscript conception, reviewing and editing, final approval.

\section{References}

1 De Baets M, Oosterhuis H. Myasthenia Gravis. Boca Raton (Florida): CRC Press; 1993. p. 17.

2 Grob D, Brunner N, Namba T, Pagala M. Lifetime course of myasthenia gravis. Muscle Nerve. 2008 Feb;37(2):141-9.

3 Wang L, Zhang Y, He M. Clinical predictors for the prognosis of myasthenia gravis. BMC Neurol. 2017 Apr;17(1):77.

4 Clendenen SR, Kostick DA. Ocular globe luxation under general anesthesia. Anesth Analg. 2008 Nov;107(5):1630-1.

5 Kunesh JC, Katz SE. Spontaneous globe luxation associated with contact lens placement. CLAO J. 2002 Jan;28(1):2-4. 

Case Reports in
Ophthalmology

\begin{tabular}{l|l}
\hline Case Rep Ophthalmol 2020;11:534-539 \\
\hline DOI: 10.1159/000509527 & $\begin{array}{l}\text { @ 2020 The Author(s). Published by S. Karger AG, Basel } \\
\text { www.karger.com/cop }\end{array}$ \\
\hline
\end{tabular}

Dam et al.: Globe Subluxation following Long-Term High-Dose Steroid Treatment for Myasthenia Gravis
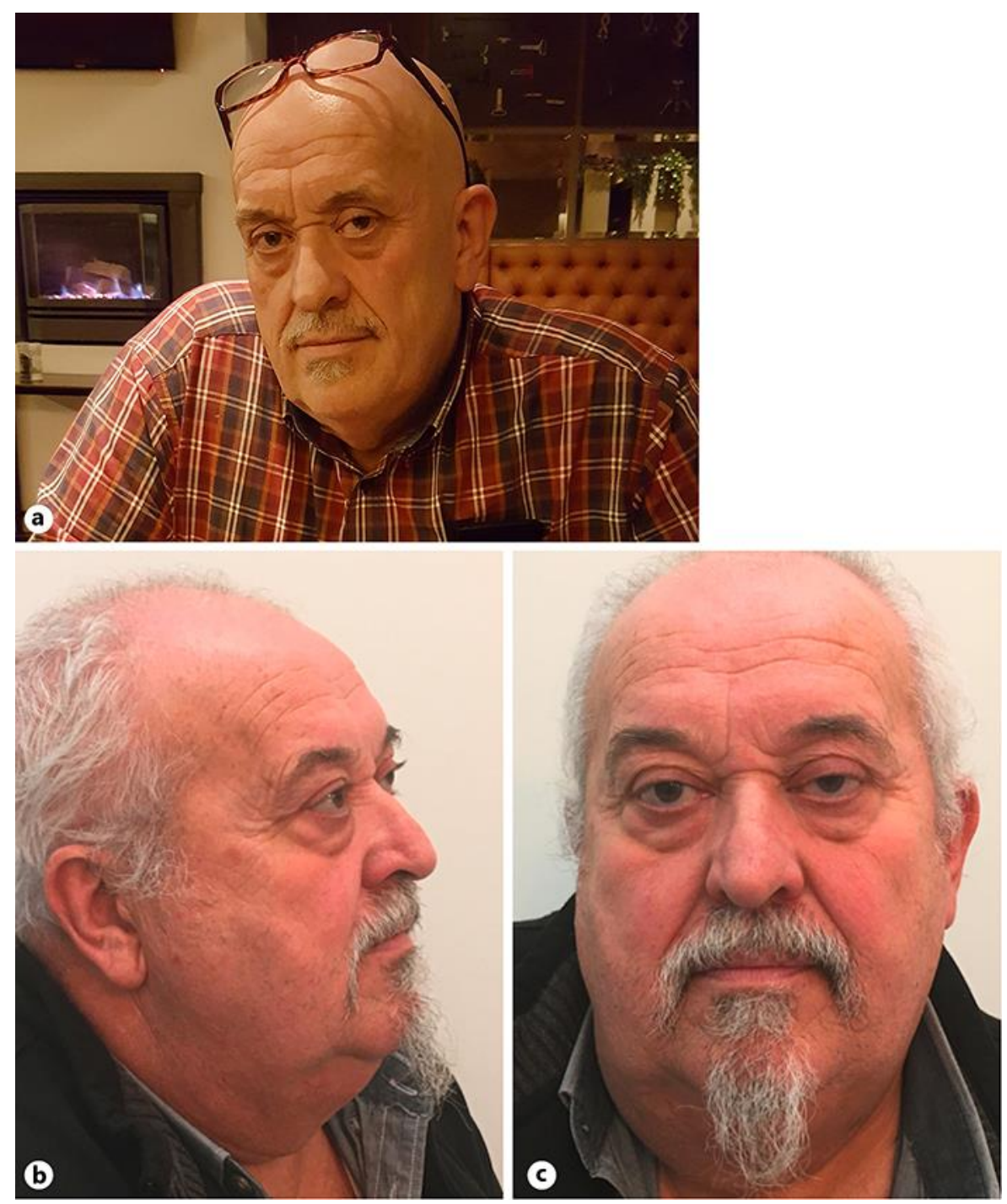

Fig. 1. a Before steroid treatment (slight proptosis visible). b, c After steroid treatment: cushingoid facies and general weight gain. 
Case Reports in Ophthalmology
Case Rep Ophthalmol 2020;11:534-539

DOI: $10.1159 / 000509527$

(c) 2020 The Author(s). Published by S. Karger AG, Basel www.karger.com/cop

Dam et al.: Globe Subluxation following Long-Term High-Dose Steroid Treatment for Myasthenia Gravis

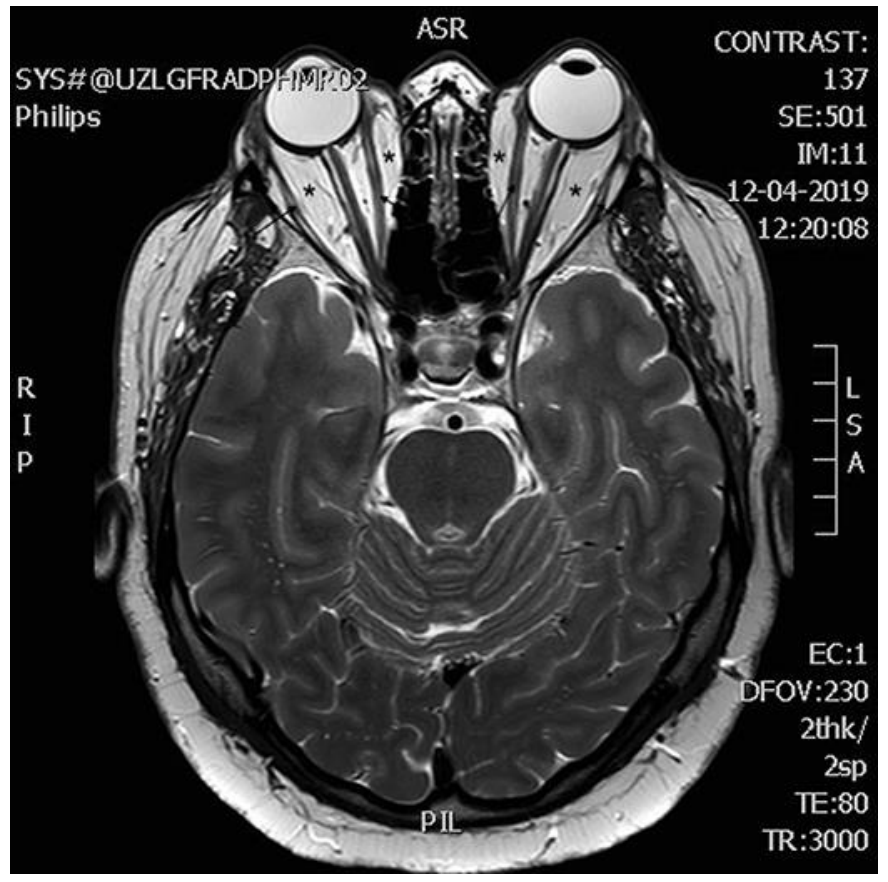

Fig. 2. MRI T2 showing bilateral exophthalmos and an increase in orbital fat $\left({ }^{*}\right)$. The rectus muscles (arrows) seem somewhat atrophic, which can be seen in myasthenia gravis patients. There are no signs of thyroid eye disease. 